\title{
Intraoperative collection of autologous platelet-rich plasma from the cardiopulmonary bypass circuit upon initiation of extracorporeal circulation
}

Takeshi Honda, Yuji Kanaoka, Hiroshi Furukawa, Taishi Tamura, Noriaki Kuwada, Takahiko Yamasawa, Yoshiko Watanabe, Yasuhiro Yunoki, Atsushi Tabuchi and Kazuo Tanemoto*

\begin{abstract}
Objectives: The aim of this study is to evaluate the possibility of the autologous platelet-rich plasma (PRP) collection from the cardiopulmonary bypass (CPB) circuit and to evaluate its effect on the aggregative function.

Methods: For seventy-two patients undergoing cardiac surgery with CPB, an autologous PRP was prepared using the Haemonetics Component Collection System ${ }^{\circledR}$ by drawing blood from the CPB circuit immediately after CPB was established. The blood samples were taken at three points for examination, A: beginning of surgery, B: immediately after heparin reversal with protamine following discontinuation of CPB, C: after the collected autologous PRP was returned to the patient. Platelet count and platelet aggregation ability were analyzed.

Results: The mean platelet count in autologous PRP was 5.5 (range: 3-14) units. Platelet count decreased by 115.0 $( \pm 27.3) \times 1000 / \mu l$ from A to B and increased by $27.3 \pm 17.2(\times 1000 / \mu l)$ from B to C.

When platelet aggregation was measured by Adenosine Diphosphate (ADP) $3.0 \mu \mathrm{M}$, it decreased by $42.6 \% \pm 12.1 \%$ from $A$ to $B$ and increased by $8.7 \% \pm 7.4 \%$ from $B$ to $C$.

Conclusions: Autologous PRP can be safely collected by drawing blood from the CPB circuit, platelet count and aggregation ability significantly decreased after CPB including autologous PRP collection. Some improvement was detected in the number of the platelets count and platelet aggregation ability by administrating an autologous PRP even if autologous PRP is collected from CPB circuit.
\end{abstract}

Trial registration: UMI-CTR, UMIN000023776. Registered 1 October 2016.

Keywords: Platelet, Cardiopulmonary bypass, Preoperative autologous platelet collection, Platelet function, Cardiac surgery

*Correspondence: tanemoto@med.kawasaki-m.ac.jp

Department of Cardiovascular Surgery, Kawasaki Medical School, 577

Matsushima, Kurashiki, Okayama, Japan

C C The Author(s). 2021 Open Access This article is licensed under a Creative Commons Attribution 4.0 International License, which permits use, sharing, adaptation, distribution and reproduction in any medium or format, as long as you give appropriate credit to the original author(s) and the source, provide a link to the Creative Commons licence, and indicate if changes were made. The images or other third party material in this article are included in the article's Creative Commons licence, unless indicated otherwise in a credit line to the material. If material is not included in the article's Creative Commons licence and your intended use is not permitted by statutory regulation or exceeds the permitted use, you will need to obtain permission directly from the copyright holder. To view a copy of this licence, visit http://creativecommons.org/licenses/by/4.0/. The Creative Commons Public Domain Dedication waiver (http://creativecommons.org/publicdomain/zero/1.0/) applies to the data made available in this article, unless otherwise stated in a credit line to the data. 


\section{Introduction}

Intraoperative thrombocyte impairment occurs in cardiac surgery due to exposure of blood to the cardiopulmonary bypass circuit; intraoperative thrombocyte impairment affects both thrombocyte count and function [1]. However, there is no established solution for this problem. Notably, platelet impairment can be treated by homologous platelet transfusion; however, platelet products tolerate a brief storage period, such that future supply may be difficult to maintain [2]. Preoperative autologous platelet-rich plasma (PRP) collection represents a potential solution, but the current method for autologous PRP collection requires approximately $90 \mathrm{~min}$ [3]. It is ideal to perform autologous PRP collection before the administration of heparin and establishment of cardiopulmonary bypass $(\mathrm{CPB})$, preoperative PRP collection delays the progress of surgery.

There have been no reports of the impact on aggregation ability of platelets collected during heparin administration immediately after the initiation of CPB. In a previous study, we confirmed that there is no difference in the aggregation ability of autologous platelets collected before and after administration of heparin and that platelet count and platelet function of PRP are not affected by heparin administration in animal experiments [4]. Based on these findings, the aim of this study is to investigate the feasibility and usefulness of autologous platelet collection from the CPB circuit after administration of heparin in clinical cases. Autologous platelet transfusion under administration of antiplatelet drug is feasible. However, because platelet aggregation ability is used to evaluate the effectiveness of autologous platelet transfusion, the patients with administration of antiplatelet drug were excluded from this study.

\section{Subjects}

This study examined one hundred and twenty-two patients who underwent cardiovascular surgery with $\mathrm{CPB}$ at Kawasaki Medical School Hospital, from November 2016 through December 2018. Patients were excluded if they met the following criteria: 1 . they did not provide consent; 2. a drug that affects platelet function was administered before surgery; 3 . they showed a high degree of anemia $(\mathrm{Hb} \leq 10 \mathrm{mg} / \mathrm{dl})$. In the excluded patients, forty were for the preoperative antiplatelet drug use mainly aspirin, seven for anemia, and one for the refusal of the patient and its family. In addition, two patients were excluded due to problems with the blood collection procedure. In all cases, the clinical study plan was explained to the patients, and the number of the subjects in this study was seventy-two (Fig. 1). This clinical study was approved by the ethics committee of Kawasaki Medical School (2478-2).

\section{Methods}

Cardiopulmonary bypass was initiated after administration of heparin at the dose of $300 \mathrm{U} / \mathrm{kg}$. By drawing blood from the CPB circuit, PRP was prepared as an autologous platelet product using the Haemonetics Component Collection System $^{\oplus}$ (Haemonetics Corporation, Boston, MA, USA) before platelet function was damaged due to prolonged $\mathrm{CPB}$ (Fig. 2). Following discontinuation of CPB, autologous PRP was returned to each patient after protamine administration.

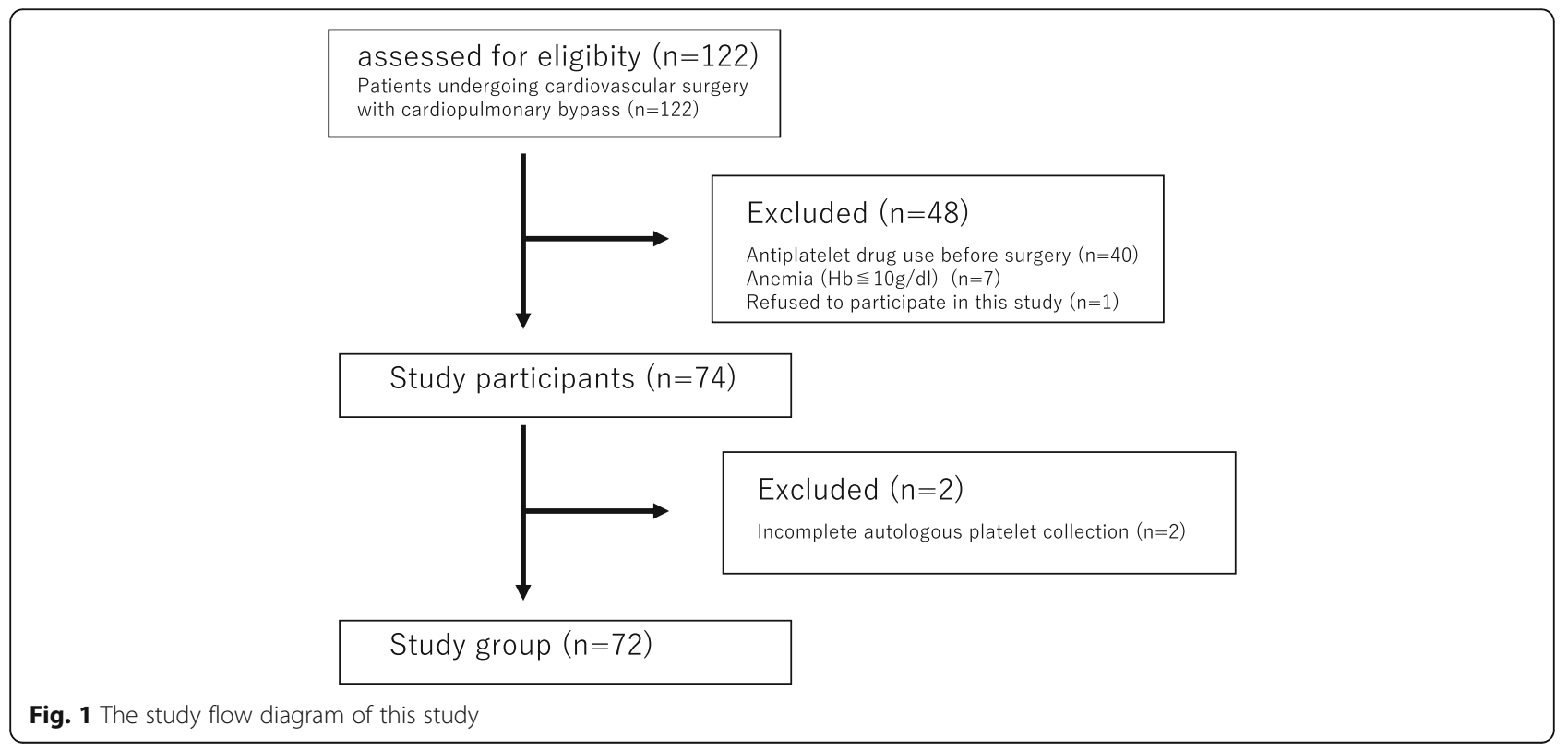




\section{a}

\section{C}
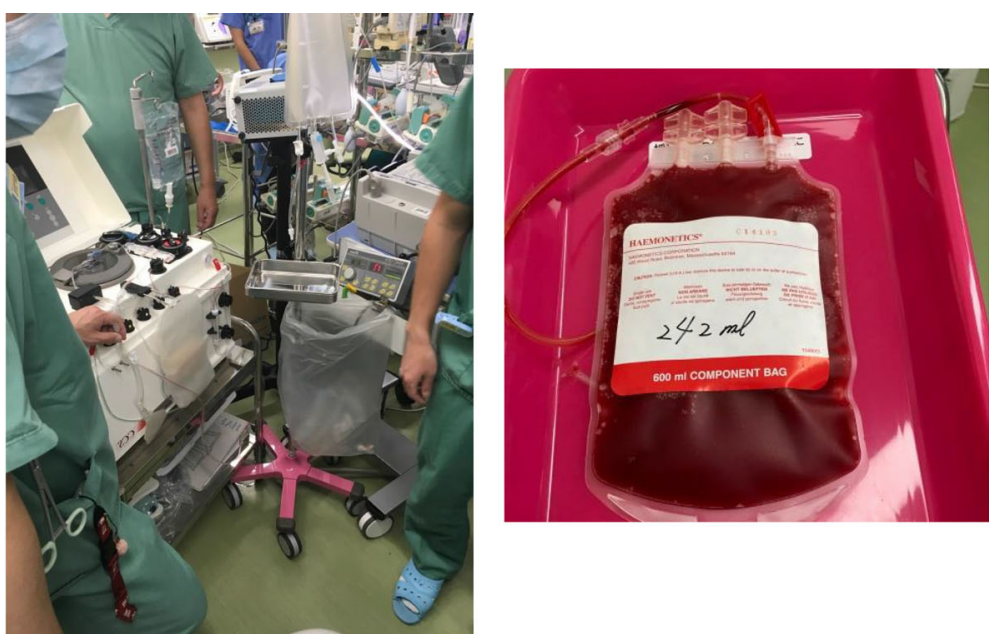

b
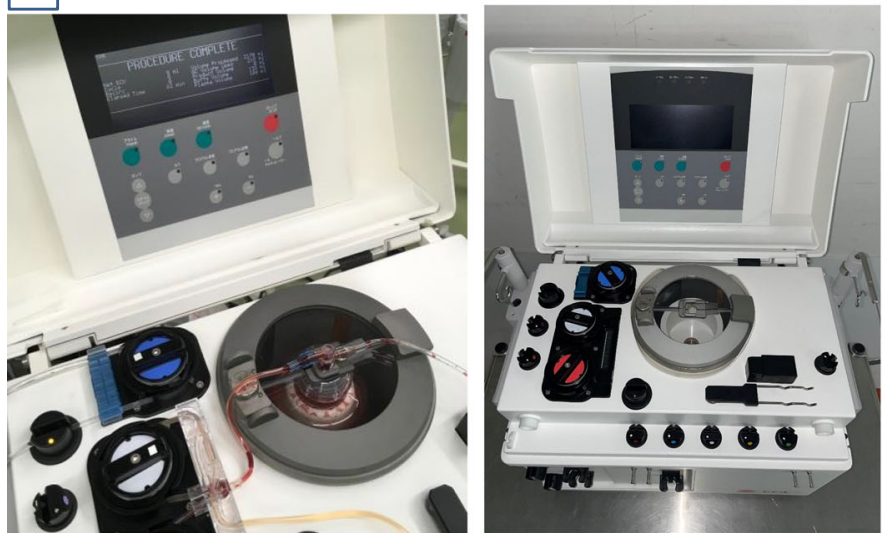

Fig. 2 The process of autologous platelet-rich plasma collection. a: Haemonetics Component Collection System ${ }^{\circledast}$ (Haemonetics, Braintree, MA, USA) is connected to the cardiopulmonary bypass circuit. b: Platelets separation started upon initiation of cardiopulmonary bypass. c: Autologous platelet-rich plasma is returned to the patient intravenously after discontinuation of cardiopulmonary bypass and administration of protamine

Blood sampling was conducted at each of the following three points, A: beginning of surgery before heparin administration, $\mathrm{B}$ : discontinuation of $\mathrm{CPB}$ and immediately after protamine administration; and $\mathrm{C}$ : after returning autologous PRP to the patient. Using these samples, platelet count and platelet aggregation ability (MCM Hema Tracer 712, MC medical, Tokyo, Japan) were measured (Fig. 3). Platelet aggregation-inducing substances were $1.0 \mu \mathrm{M}$ ADP, $3.0 \mu \mathrm{M}$ ADP, $0.25 \mu \mathrm{g} / \mathrm{ml}$ collagen, and $2.0 \mu \mathrm{g} / \mathrm{ml} \mathrm{col-}$ lagen. Significant differences were assessed by comparing blood from each of the time points using the Student's ttest. A $p$ value of $<0.05$ was considered to be statistically significant. All analyses were performed using SPSS Ver. 20.0 (IBM SPSS; Armonk NY, USA).

\section{Results}

In total, seventy-two patients were included. Mean patient age was $72.4 \pm 12.9$ years. The male/female ratio was 49:23. The types of surgery consisted of forty-two cases of valvular disease surgery, twenty-six cases of aortic aneurysm surgery, and four cases of coronary artery bypass surgery + others. The mean operation time was $378.6 \pm 141.8 \mathrm{~min}$, and the mean number of platelets at the initiation of surgery was $182.3 \pm 31.6 \times 1000 / \mu \mathrm{l}$ (Table 1). The mean platelet count in autologous PRP was $120.8 \pm 69.3 \times 10^{11}$, corresponding to approximately 5.5 units (Table 2).

From point $\mathrm{A}$ to point $\mathrm{B}$, the reduction in platelet count was $118.3 \pm 31.4 \times 1000 / \mu \mathrm{l}$. The increase in platelet count from point $B$ to point $C$ was $27.3 \pm$ $17.2 \times 1000 / \mu \mathrm{l}$ (Fig. 4). The transition of maximum agglutination ability was measured by four methods depending on the aggregation-inducing agent. When using ADP $1.0 \mu \mathrm{M}$, maximum agglutination ability decreased by $36.9 \pm 15.9 \%$ from point $A$ to point $B$ and increased by $4.3 \pm 7.8 \%$ from point $\mathrm{B}$ to point $\mathrm{C}$. 


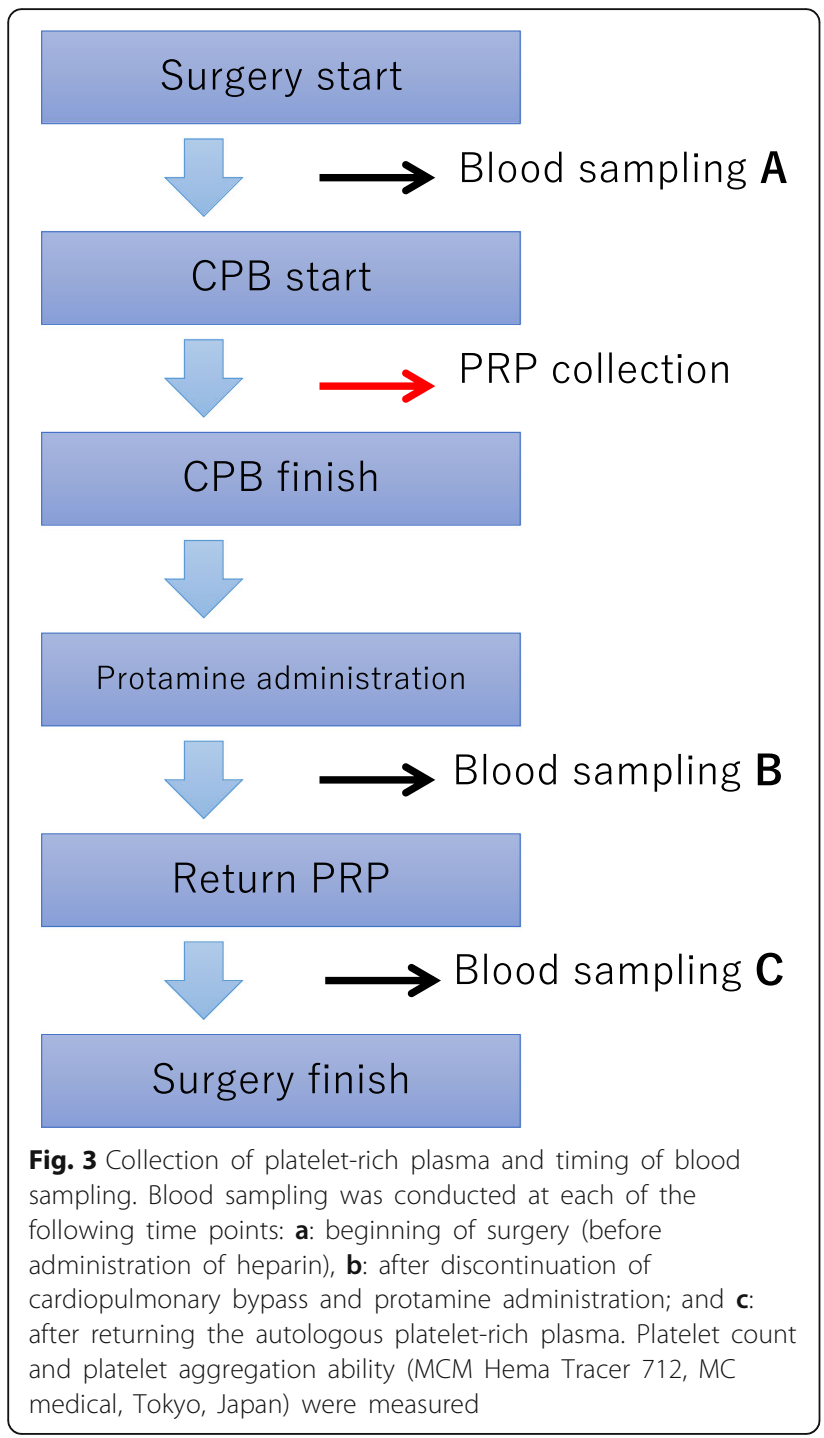

When using ADP $3.0 \mu \mathrm{M}$, maximum agglutination ability decreased by $36.9 \pm 15.9 \%$ from point $A$ to point B and increased by $8.7 \pm 7.4 \%$ from point $B$ to point $C$. When using collagen $0.25 \mu \mathrm{g} / \mathrm{ml}$, maximum agglutination ability decreased by $29.3 \pm 24.1 \%$ from point $\mathrm{A}$ to point $\mathrm{B}$ and decreased from point $\mathrm{B}$ to point $C$ by $1.0 \pm 2.8 \%$ (Fig. 5). When using collagen $2.0 \mu \mathrm{g} / \mathrm{ml}$, maximum agglutination ability decreased by $44.0 \pm 15.9 \%$ from point $\mathrm{A}$ to point $\mathrm{B}$ and increased by $9.6 \pm 9.4 \%$ from point B to point C (Fig. 6).

We analyzed the results of 46 patients with normothermic valvular/CABG operation (normothermic valvular surgery group) and 26 patients with hypothermic aortic operation (hypothermic aortic surgery group) separately. Operative time, CPB time and cross clamp time were significantly longer in the hypothermic aortic surgery group, and lowest body temperature was significantly lower in hypothermic
Table 1 Patient characteristics and operative data

\begin{tabular}{lll}
\hline Factors $(\boldsymbol{n}=\mathbf{7 2})$ & Mean & SD \\
\hline Age (years) & 72.4 & 12.9 \\
Male/Female & $49: 23$ & \\
Height $(\mathrm{cm})$ & 157.8 & 8.6 \\
Weight $(\mathrm{kg})$ & 61.0 & 13.6 \\
Body mass index & 23.7 & 4.2 \\
Body surface area $\left(\mathrm{m}^{2}\right)$ & 1.62 & 0.20 \\
Procedure $(n=72)$ & & \\
$\quad$ Aortic & 26 & \\
$\quad$ Valvular & 42 & \\
$\quad$ Coronary + others & 4 & \\
Operation time (min) & 378.6 & 141.8 \\
Extracorporeal circulation time (min) & 129.3 & 44.6 \\
Aortic cross-clamp time (min) & 93.6 & 33.0 \\
Selective cerebral perfusion time $(\mathrm{min})(n=20)$ & $\mathbf{6 8 . 7}$ & $\mathbf{4 1 . 3}$ \\
Lowest temperature ( $\left.{ }^{\circ} \mathrm{C}\right)$ & 32.7 & 3.5 \\
Drain bleeding within 24 $\mathrm{h}$ postoperatively $(\mathrm{ml})$ & 551.6 & 353.0 \\
Reoperation & & 0 \\
\hline
\end{tabular}

Table 2 Platelet count and maximum aggregation ability

\begin{tabular}{|c|c|c|}
\hline Factors & Mean & SD \\
\hline Collected platelet-rich plasma (ml) & 233.3 & 43.5 \\
\hline Buffy (ml) & 128.3 & 34.0 \\
\hline Plasma (ml) & 104.5 & 18.6 \\
\hline Number of platelets in platelet-rich plasma $\left(\times 10^{11}\right)$ & 120.8 & 69.3 \\
\hline Number of platelets in A blood $(\times 1000 / \mu l)$ & 182.3 & 31.6 \\
\hline Number of platelets in B blood $(\times 1000 / \mu l)$ & 63.5 & 30.5 \\
\hline Number of platelets in C blood $(\times 1000 / \mu \mathrm{l})$ & 93.4 & 43.1 \\
\hline \multicolumn{3}{|l|}{ Maximum aggregation rate in $\mathrm{A}$ blood } \\
\hline $1.0 \mu \mathrm{M}$ ADP (\%) & 54.7 & 17.6 \\
\hline $3.0 \mu \mathrm{M}$ ADP $(\%)$ & 68.9 & 13.0 \\
\hline $0.25 \mu \mathrm{g} / \mathrm{ml}$ collagen (\%) & 40.5 & 25.3 \\
\hline $2.0 \mu \mathrm{g} / \mathrm{ml}$ collagen (\%) & 72.7 & 14.5 \\
\hline \multicolumn{3}{|l|}{ Maximum aggregation rate in B blood } \\
\hline $1.0 \mu \mathrm{M}$ ADP (\%) & 17.4 & 5.8 \\
\hline $3.0 \mu \mathrm{M}$ ADP $(\%)$ & 25.4 & 10.8 \\
\hline $0.25 \mu \mathrm{g} / \mathrm{ml}$ collagen (\%) & 10.5 & 4.2 \\
\hline $2.0 \mu \mathrm{g} / \mathrm{ml}$ collagen (\%) & 28.5 & 16.9 \\
\hline \multicolumn{3}{|l|}{ Maximum aggregation rate in $\mathrm{C}$ blood } \\
\hline $1.0 \mu \mathrm{M}$ ADP (\%) & 21.7 & 9.5 \\
\hline $3.0 \mu \mathrm{M}$ ADP (\%) & 34.1 & 14.1 \\
\hline $0.25 \mu \mathrm{g} / \mathrm{ml}$ collagen (\%) & 9.5 & 2.9 \\
\hline $2.0 \mu \mathrm{g} / \mathrm{ml}$ collagen (\%) & 38.1 & 19.6 \\
\hline
\end{tabular}

A: Beginning of surgery (before administration of heparin) B: After discontinuation of cardiopulmonary bypass and protamine administration

C: After returning autologous platelet-rich plasma 


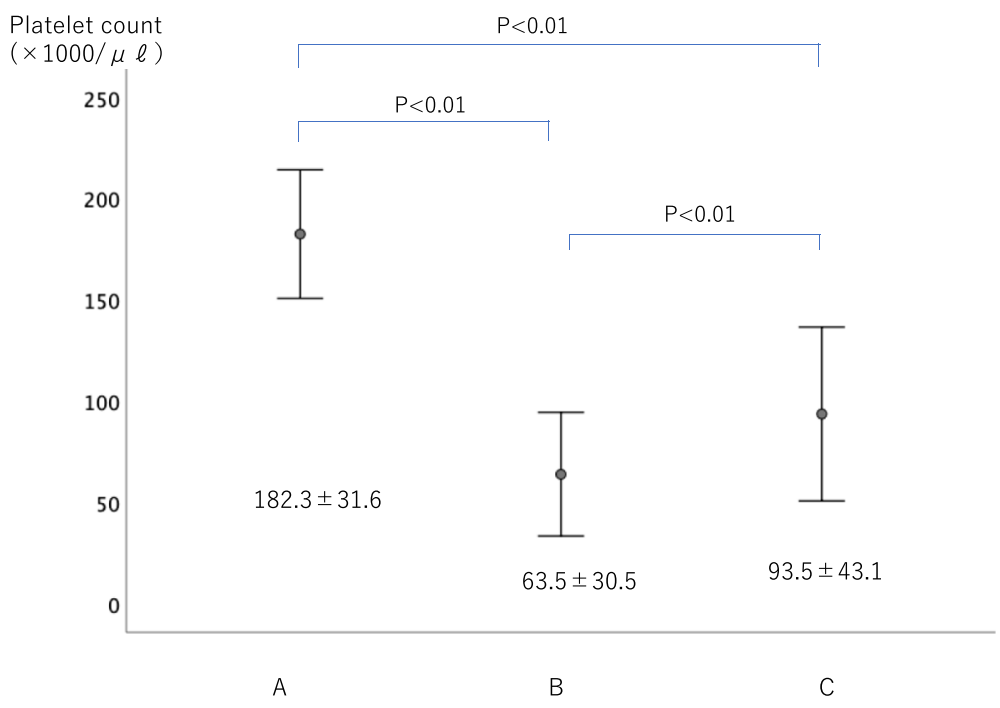

Fig. 4 Change of platelet count during surgery. The platelet count significantly decreased after CPB including autologous PRP collection. A significant increase in platelet count was observed upon returning autologous platelet-rich plasma to the patients

aortic surgery group. Moreover, the ratio that needed a platelet blood transfusion was significantly higher in hypothermic aortic surgery group. However, no significant differences were observed between the groups in terms of blood loss volume after operation (Table 3).

When the normothermic valvular surgery and hypothermic aortic surgery groups were compared, no differences were observed with regard to the platelet count (Fig. 7), aggregation ability (Figs. 8, 9) during surgery including autologous PRP collection and autologous PRP return.

\section{Discussion}

The number of platelets reportedly decreases by $30-$ $50 \%$ during extracorporeal circulation $[5,6]$. The suspected causes include dilution by CPB introduction, damage due to flow in a nonphysiological environment, and activation of platelet aggregation [7]. Autologous platelet collection is a method for preservation of platelets before mechanical damage during $\mathrm{CPB}$, which is returned to the patient after the CPB has been discontinued; it can avoid consumption due to platelet damage and activation $[3,8]$. However, this method is limited in its usefulness, because it requires approximately $90 \mathrm{~min}$ for collection,

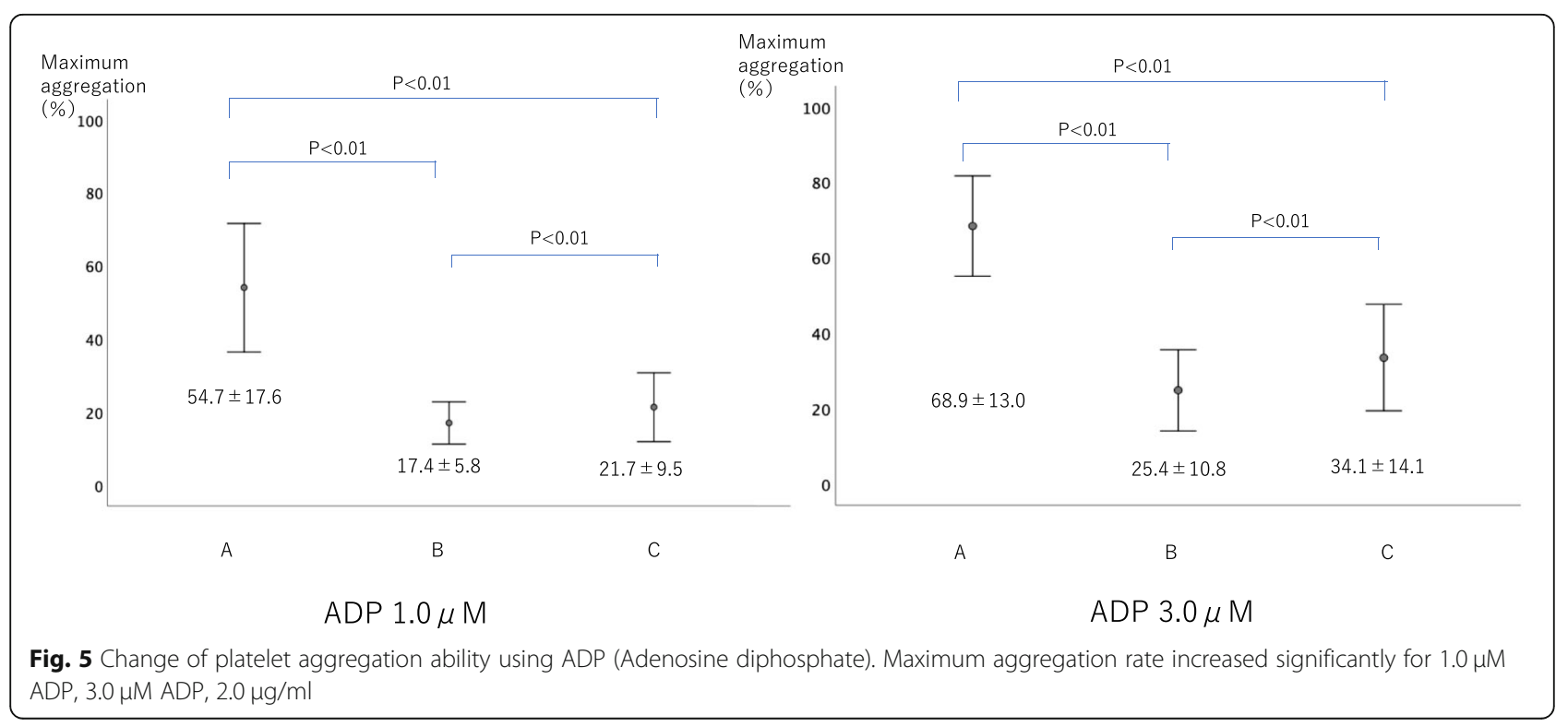



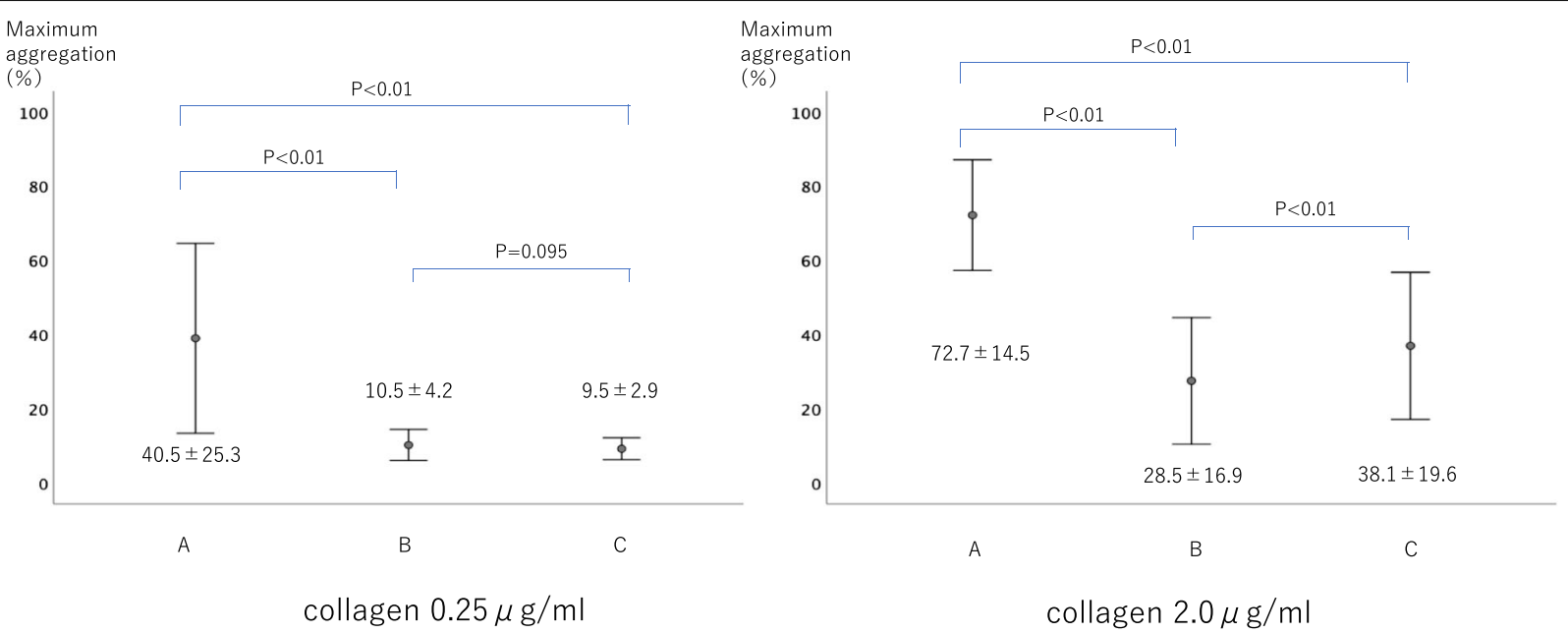

Fig. 6 Change of platelet aggregation ability using collagen. Maximum aggregation rate increased significantly for collagen $2.0 \mu \mathrm{g} / \mathrm{ml}$. However, an increase in maximum aggregation rate was not observed in $0.25 \mu \mathrm{g} / \mathrm{ml}$ collagen due to its low reagent concentration

after induction of anesthesia and prior to introduction of heparin.

Platelet function is reportedly inhibited by various antiplatelet drugs; however, inhibition of platelet function during administration of heparin has not been shown to occur other than in cases of heparin-induced thrombocytopenia (HIT) [9], in which antibodies promote the production of antiplatelet factor 4 heparin complex antibody, thereby promoting platelet aggregation [10].

There has been no study regarding the effects of heparin administration before $\mathrm{CPB}$ on platelet aggregation. We previously reported that there was no difference in autologous platelet aggregation between those collected before and after heparin administration in an animal model. We concluded that platelet count and platelet function in PRP are not affected by heparin administration [4]. Based on this experimental result, we planned the present collection of autologous platelets from blood after administration of heparin at the early stage of $\mathrm{CPB}$ initiation. The present results indicate that it is clinically feasible to collect autologous platelets from $\mathrm{CPB}$ circuit. This is consistent with the observation study which demonstrated that plasma components, platelet count, and platelet aggregation can be restored when plasma and platelets are sequestered at the time of $\mathrm{CPB}$ and subsequently returned after the procedure [11]. This autologous PRP collection from CPB circuit seems to be feasible and safe. Platelet count and aggregation ability had improved after the return of autologous PRP in this study. However, platelet count and aggregation ability significantly decreased after $\mathrm{CPB}$ including

Table 3 Clinical outcomes in normothermic valvular operation and hypothermic aortic operation

\begin{tabular}{llll}
\hline & Normothermic valvular surgery & Hypothermic aortic surgery & $\boldsymbol{p}$ value \\
\hline Number of patients & 46 & 26 & - \\
Age & $71.4 \pm 14.3$ & $73.8 \pm 9.6$ & 0.402 \\
Gender (male) & $29(63.0 \%)$ & $20(80.1)$ & 0.095 \\
BSA $\left(\mathrm{m}^{2}\right)$ & $1.61 \pm 0.22$ & $1.67 \pm 0.15$ & 0.274 \\
Platelet count $\left(\times 10^{4}\right)$ & $19.1 \pm 4.3$ & $17.2 \pm 2.8$ & 0.725 \\
Operative time $(\mathrm{min})$ & $327.7 \pm 80.6$ & $464.2 \pm 173.6$ & $P<0.05$ \\
CPB time (min) & $149.0 \pm 40.7$ & $242.5 \pm 89.2$ & $P<0.05$ \\
Clamp time (min) & $80.4 \pm 10.8$ & $126.8 \pm 44.5$ & $P<0.05$ \\
Body temperature $\left({ }^{\circ} \mathrm{C}\right)$ & $34.7 \pm 0.6$ & $27.9 \pm 3.4$ & $P<0.05$ \\
Blood loss after surgery $(\mathrm{ml})$ & $522.3 \pm 326.7$ & $589.0 \pm 395.1$ & 0.48 \\
Re-thoracotomy for bleeding & 0 & 0 & 1.0 \\
Homologous platelet transfusion & $12 / 46(26.1 \%)$ & $21 / 26(80.8 \%)$ & $P<0.05$ \\
\hline
\end{tabular}




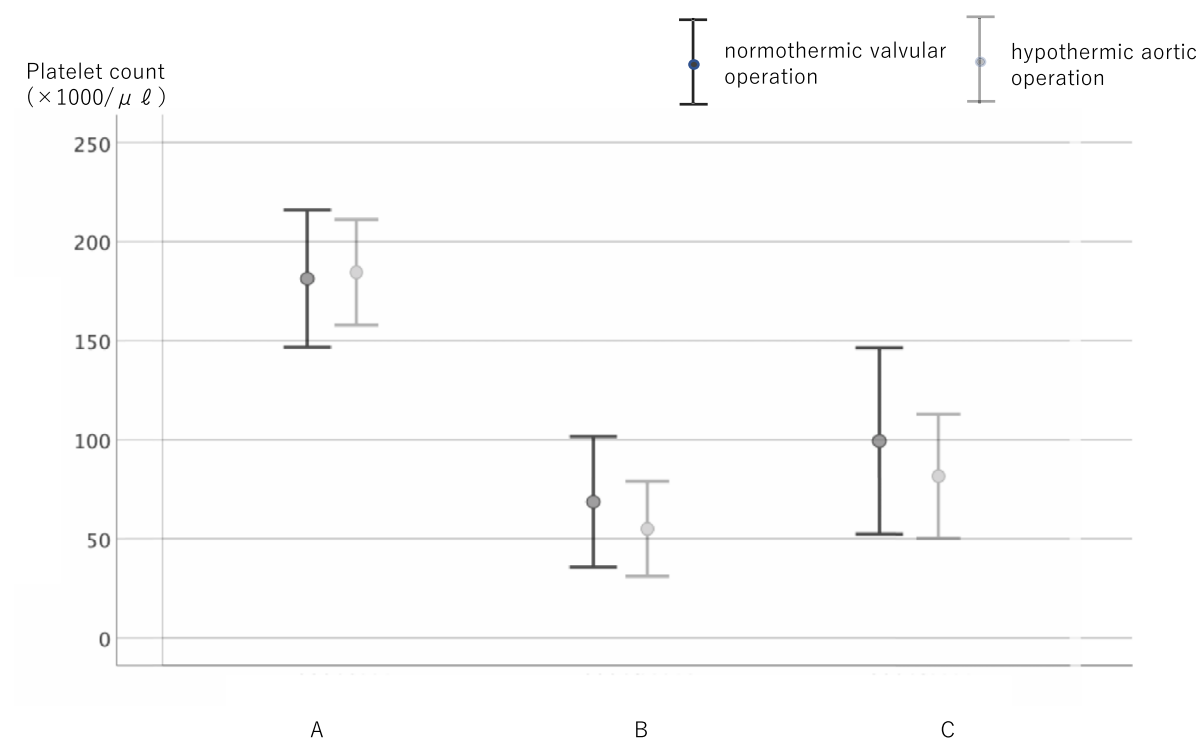

Fig. 7 Change of platelet count during surgery in normothermic valvular operation and hypothermic aortic operation. No significant differences were observed between the groups in terms of platelet count during surgery

autologous PRP collection. It was unclear whether significant decrease of platelet count and aggregation ability is due to CPB, autologous PRP collection, or both. Autologous PRP collection may have the risk of bleeding tendency after CPB because of significant decrease of platelet count and aggregation ability. Further examination is necessary to clarify this concern.

The number of patients that anti-platelet drugs are given has increased because less invasive endovascular interventions are developed, and will increase in future. We have excluded the patients with preoperative antiplatelet drug use to evaluate accurate platelet aggregation ability in this study. Platelet aggregation ability had recovered after a certain period of cessation time. We have reported that the platelet aggregation ability had already recovered at 5 days after clopidogrel cessation [12].

Therefore, we think that autologous PRP collection is also useful for the patient with antiplatelet drug use.

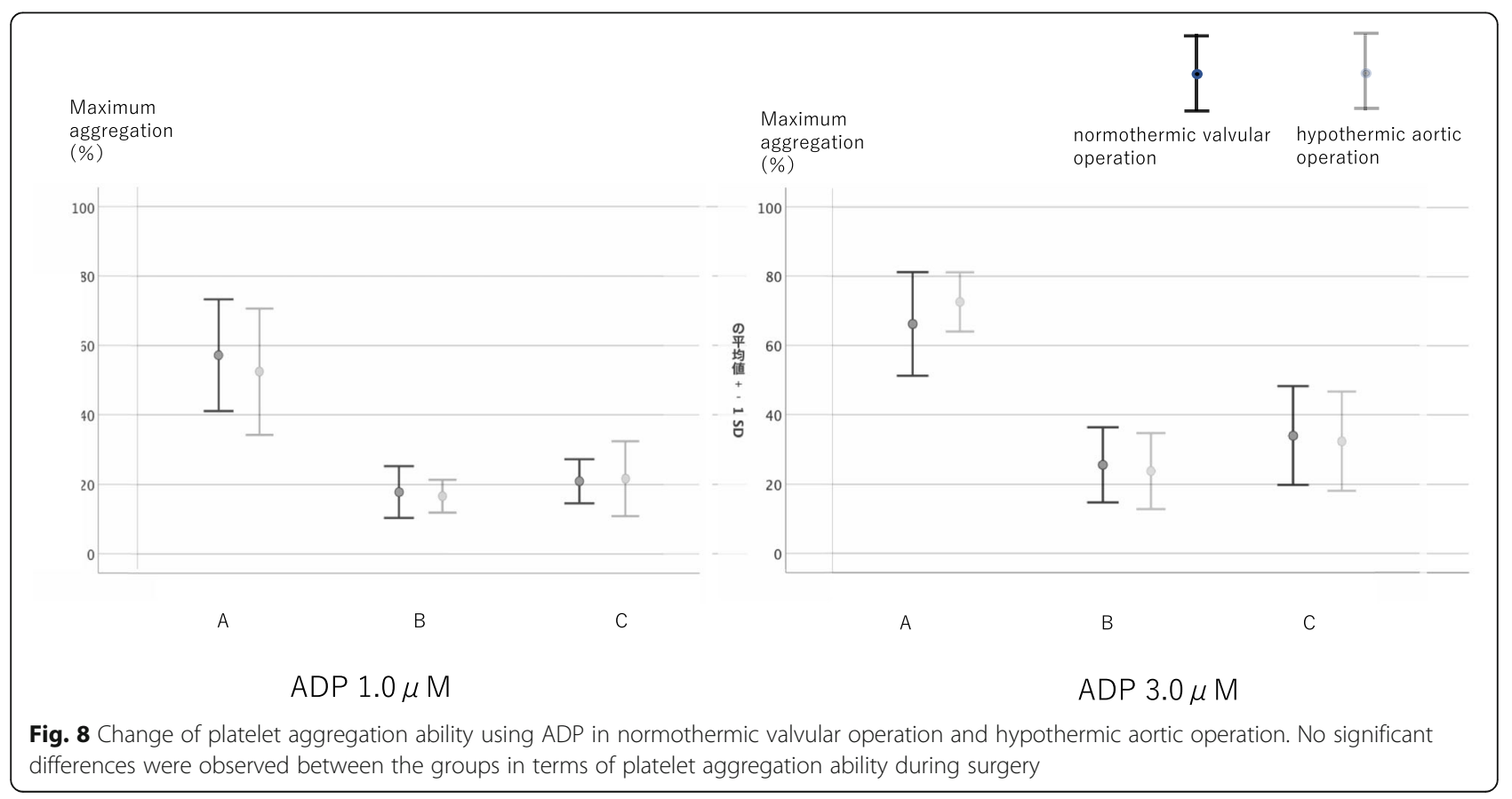




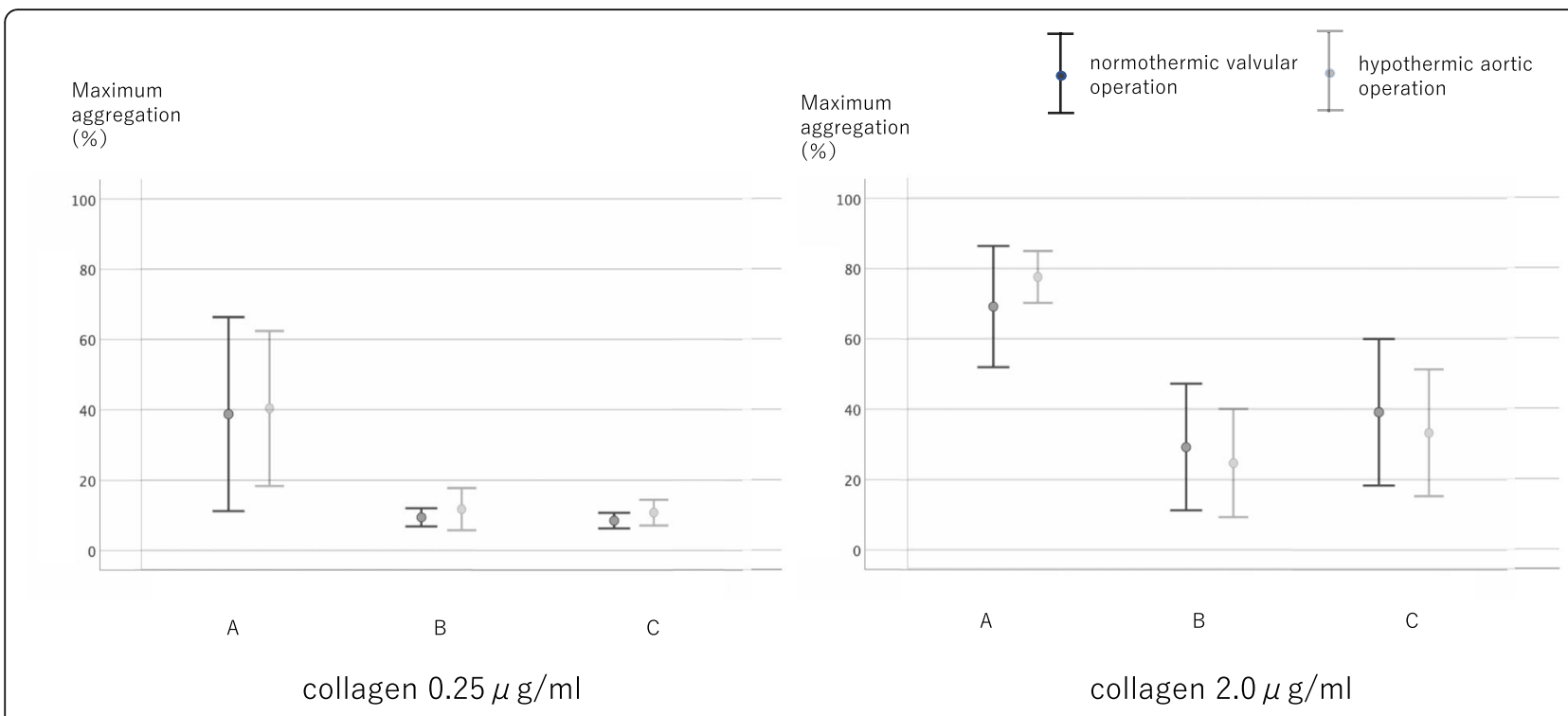

Fig. 9 Change of platelet aggregation ability using collagen in normothermic valvular operation and hypothermic aortic operation. No significant differences were observed between the groups in terms of platelet aggregation ability during surgery

Recently, a meta-analysis concerning the autologous PRP have been reported which mention its usefulness in surgery with CPB [8].

The present study was limited in that the subjects were not compared with a control group. Moreover, there was no indicator other than coagulation ability to accurately determine the extent of platelet damage by cardiopulmonary bypass; other indices are influenced by various factors. We will evaluate the usefulness of the autologous PRP collection from CPB circuit by means of comparison between the cases with autologous PRP collection and without autologous PRP collection in future.

\section{Conclusions}

It was possible to collect autologous platelets with effective agglutination ability from the cardiopulmonary bypass circuit. Both blood platelet count and aggregation ability were increased by returning autologous PRP to patients after the discontinuation of cardiopulmonary bypass. This approach may represent an effective countermeasure to the shortage of blood products that our society is likely to encounter in the near future.

\section{Abbreviations}

PRP: Platelet-rich plasma; CPB: Cardiopulmonary bypass; ADP: Adenosine Diphosphate; HIT: Heparin-induced thrombocytopenia

\section{Acknowledgments}

The authors thank Medical English Service (https://www.med-english.com) for the English language review.

\section{Authors' contributions}

TH wrote this manuscript. KT, TY, HF, and YK performed the operation. KT, $H F$, YK revised the manuscript. All authors read and approved the final manuscript.
Funding

This work was supported by JSPS KAKENHI Grant Number JP15K10247.

\section{Availability of data and materials}

The datasets used and analyzed during the current study are available from the corresponding author on reasonable requests.

\section{Ethics approval and consent to participate}

The present study was approved by the ethics committee of Kawasaki Medical School (2478-2), written informed consent was obtained from all of the patients.

\section{Consent for publication}

Not applicable.

\section{Competing interests}

The authors declare that they have no competing interests.

Received: 13 May 2020 Accepted: 26 December 2020

Published online: 05 February 2021

\section{References}

1. Stover EP, Siegel LC, Hood PA, O'Riordan GE. Platelet-rich plasmapheresis with therapeutic platelet yield reduces allogenic red cell and platelet transfusions in high risk cardiac surgery. Anesthesiology. 1996;85:A68.

2. Kleinman $\mathrm{S}$, Chan P, Robillard P. Risks associated with transfusion of cellular blood components in Canada. Transfus Med Rev. 2003;17:120-62.

3. Zhou SF, Estrera AL, Loubser P, Ignacio C, Panthayi S, Miller III, et al. Autologous platelet-rich plasma reduces transfusions during ascending aortic arch repair: a prospective, randomized, controlled trial. Ann Thorac Surg. 2015;99:1282-90.

4. Takiuchi $\mathrm{H}$, Tanemoto K. Impact of systemic heparinization on platelet function in autologous platelet-rich plasma. Kawasaki Med J. 2015;41:143-51.

5. Verrier ED, Boyle EM Jr. Endothelial cell injury in cardiovascular surgery. Ann Thorac Surg. 1996;62:915-22.

6. Sakatsume K, Saiki Y. Coagulation factors in artificial circulation. J Artif Organs. 2016:45:221-4

7. Edmunds LH. Managing fibrinolysis without aprotinin. Ann Thorac Surg. 2010:89:324-31.

8. Zhai Q, Wang Y, Yuan Z, Zhang R, Tian A. Effects of platelet-rich plasmapheresis during cardiovascular surgery: A meta-analysis of randomized controlled clinical trials. J Clin Anesth. 2019;56:88-97. 
9. Pabst D, Boone JB, Soleimani B, Brehm CE. Heparin-induced thrombocytopenia in patients on extracorporeal membrane oxygenation and the role of a heparin-bounded circuit. Perfusion. 2019;34:584-9.

10. Amiral J, Bridey F, Dreyfus M, Vissac AM, Fressinaud E, Wolf M, et al. Platelet factor 4 complexed to heparin is the target for antibodies generated in heparin-induced thrombocytopenia. Thromb Haemost. 1992;68:95-6.

11. Koster A, Sanger S, Knörig FJ, Kuppe H, Hetzer R, Loebe M. Autologous plasma and platelet sequestration at the beginning of cardiopulmonary bypass: a pilot investigation in five patients undergoing extended vascular surgery in deep hypothermia. ASAIO J. 2002;48:106-9.

12. Takiuchi $\mathrm{H}$, Tanemoto K. Optimal timing of clopidogrel discontinuation in Japanese patients: platelet aggregation test using the VerifyNow ${ }^{\circledR}$ system. Gen Thorac Cardiovasc Surg. 2015;63:601-6.

\section{Publisher's Note}

Springer Nature remains neutral with regard to jurisdictional claims in published maps and institutional affiliations.

Ready to submit your research? Choose BMC and benefit from:

- fast, convenient online submission

- thorough peer review by experienced researchers in your field

- rapid publication on acceptance

- support for research data, including large and complex data types

- gold Open Access which fosters wider collaboration and increased citations

- maximum visibility for your research: over $100 \mathrm{M}$ website views per year

At BMC, research is always in progress.

Learn more biomedcentral.com/submissions 